\title{
Design and Realization of Band Pass Filter in K-Band Frequency for Short Range Radar Application
}

\author{
Arie Setiawan a,*, Taufiqqurrachman a, Adam Kusumah Firdaus ${ }^{\text {b }}$, Fajri Darwis a, \\ Aminuddin Rizal c, Winy Desvasari a, Hana Arisesa a, Sulistyaningsih a, \\ Prasetyo Putranto a, Nasrullah Armi a, Dharu Arseno ${ }^{b}$ \\ ${ }^{a}$ Research Center for Electronics and Telecommunication \\ Indonesian Institute of Sciences \\ Jl. Sangkuriang - Komplek LIPI \\ Bandung, Indonesia \\ ${ }^{b}$ Telecommunication Engineering, Faculty of Electrical Engineering \\ Telkom University \\ Jl. Telekomunikasi Terusan Buah Batu \\ Bandung, Indonesia \\ ${ }^{c}$ Computer Engineering Department \\ Universitas Multimedia Nusantara \\ Jl. Scientia Boulevard, Gading, Serpong \\ Tangerang, Indonesia
}

\begin{abstract}
Short range radar (SRR) uses the K-band frequency range in its application. The radar requires high-resolution, so the applied frequency is $1 \mathrm{GHz}$ wide. The filter is one of the devices used to ensure only a predetermined frequency is received by the radar system. This device must have a wide operating bandwidth to meet the specification of the radar. In this paper, a band pass filter (BPF) is proposed. It is designed and fabricated on RO4003C substrate using the substrate integrated waveguide (SIW) technique, results in a wide bandwidth at the K-band frequency that centered at $24 \mathrm{GHz}$. Besides the bandwidth analysis, the analysis of the insertion loss, the return loss, and the dimension are also reported. The simulated results of the bandpass filter are: VSWR of 1.0308 , a return loss of $-36.9344 \mathrm{~dB}$, and an insertion loss of $-0.6695 \mathrm{~dB}$. The measurement results show that the design obtains a VSWR of 2.067, a return loss of $-8.136 \mathrm{~dB}$, and an insertion loss of $-4.316 \mathrm{~dB}$. While, it is obtained that the bandwidth is reduced by about $50 \%$ compared with the simulation. The result differences between simulation and measurement are mainly due to the imperfect fabrication process.
\end{abstract}

Keywords: Short range radar, band pass filter, microstrip, substrate integrated waveguide, K-band.

\section{INTRODUCTION}

In the original K-band, there is a water vapor absorption line at $22.2 \mathrm{GHz}$ which causes a serious problem of attenuation in some applications. The radar echo from rain can limit the capability of radars at these frequencies [1]. However, K-band frequency range is still attractive for a small size radar that is used for an application that does not require long-range detection. Several fields such as automotive industry utilize short range radar (SRR) for road safety and intelligent transport systems [1]-[3].

Automotive short range radar (SRR) provides various functions to increase drivers' safety and convenience. For SRR to have sufficiently high range resolution for detecting small objects at close range, it requires a wide bandwidth. The availability of wide bandwidth significantly improves range resolution which results in better separation of objects. With higher range

\footnotetext{
* Corresponding Author.

Email: setiawan.ari3@gmail.com

Received: December 07, 2020 ; Revised: December 31, 2020

Accepted: January 19, 2021 ; Published: August 31, 2021

Open access under CC-BY-NC-SA

(C) 2021 PPET - LIPI
}

resolution, it improves an SRR system's minimum distance of detection.

There are several devices that are part of the SRR system, one of which is the filter. A filter with certain specifications is needed so that it can be used in SRR systems. To have a filter designed with a low insertion loss, small size, and limited cost is essential for the manufacture of microwave systems. Unfortunately, the traditional technology, either planar or non-planar, is incapable to provide all these characteristics at the same time. In fact, the rectangular waveguides present low insertion losses and good selectivity [4]. Recently, a substrate integrated waveguide (SIW) is one popular method to design microstrip filters. This method is similar to the conventional rectangular waveguide, and can be used in the K-band frequency range in order to meet the bandwidth and filter characteristics requirement, including insertion loss, return loss, and minimization of filter dimensions. Figure 1 shows the similarity of the electric field distribution in the SIW and equivalent conventional waveguide. In the SIW filter structure, the via sequences are connected between the top and bottom of the conductor forming a cavity wall, where the microstrip transmission line is used for the feeding of the RF input and output. 


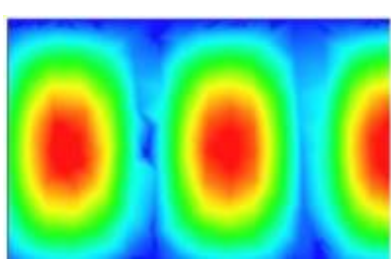

(a) Waveguide

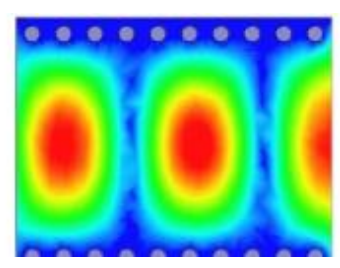

(b) SIW
Figure 1. Comparison of Waveguide and SIW Filter [5].

The cavity wall consists of via rows that provide outof-band rejection, making it perfect to be used in radar applications [6]. Basically, the microstrip transmission line is also functioned to guide a signal that enters a device. However, the thing that makes SIW different from other microstrips is the presence of the two rows of metal cylinders, causing low-frequency signals to not propagate in the SIW [7]. Also, a wide operating bandwidth can be achieved using the SIW, as reported in [8]-[9]. In [8], a hybrid and periodically drilled SIW (PDSIW) structure are proposed. While in [9], a substrate integrated plasmonic waveguide (SIPW) concept is used to obtain a wide bandwidth.

In this paper, a design of wideband band pass filter (BPF) using the SIW technique is proposed. The device is designed and fabricated on RO4003C substrate. This $\mathrm{BPF}$ will operates at the K-band with a center frequency of $24 \mathrm{GHz}$.

\section{Filter DESIGN AND Simulation}

\section{A. Design Methodology}

The proposed design of bandpass filter is intended to pass signals at the center frequency of $24 \mathrm{GHz}$ with a bandwidth of $1 \mathrm{GHz}$. The bandpass filter is designed as a part of the SRR block system. The flow chart of the filter design stages is depicted in Figure 2. It is started by determining the filter specification and dimension, followed by simulation and realization. Filter performances must meet the value of certain parameters such as insertion loss, return loss, and VSWR.

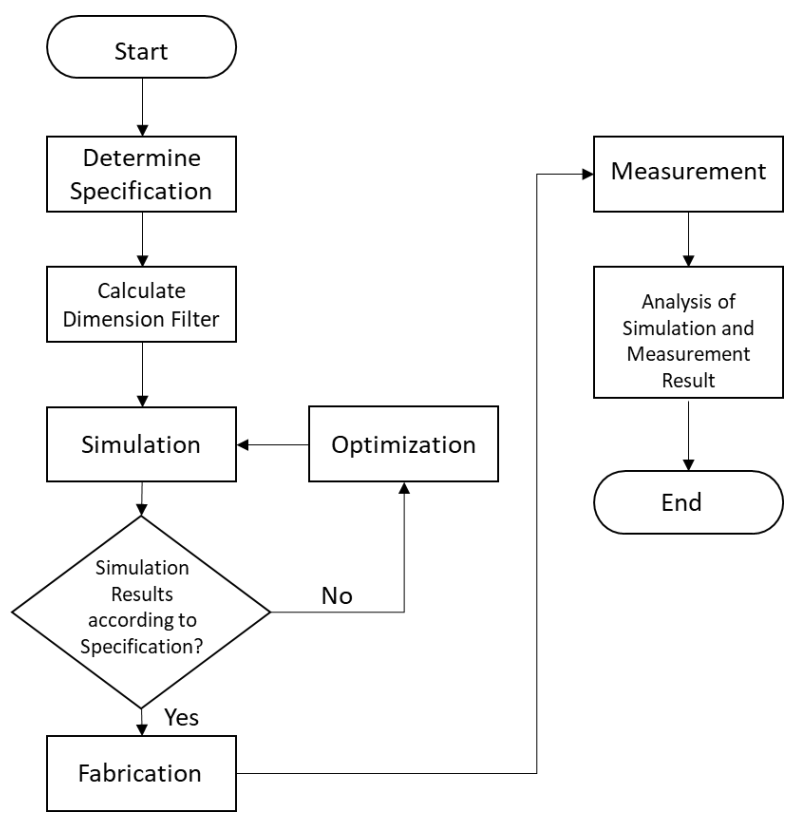

Figure 2. Flowchart of Filter Design.
The filter specifications are as follows:

- Frequency Range : $: 23.5 \mathrm{GHz}-24.5 \mathrm{GHz}$

- Center Frequency : $24 \mathrm{GHz}$

- Bandwidth $: 1 \mathrm{GHz}$

- Return Loss $\quad: \leq-10 \mathrm{~dB}$

- Insertion Loss $\quad: \geq-3 \mathrm{~dB}$

- VSWR $\quad: \leq 2$

- Frequency Response: Chebyshev

- Substrate : Rogers RO4003C

(Thickness: $0.813 \mathrm{~mm}$ )

(Dielectric Constant (Er): 3.55)

After determining the specifications, next step is to calculate the dimensions of the filter. This process includes determining the order, the diameter, and the distance between the vias using a predetermined formula. Afterward, the simulation is conducted to obtain Sparameter values of the designed filter with calculated dimensions in the previous stage. If the simulation results are not in accordance with the specifications, optimization will be carried out, but if the simulation results have met the requirements, the filter design will be fabricated. The filter that has been fabricated will then be measured and compared with the simulation results. Then, the difference between the two results will be analyzed.

\section{B. Substrate Integrated Waveguide (SIW)}

The characteristics of SIW are similar to that of a rectangular waveguide. The combination of a non-planar circuit (waveguide) and a planar shape (microstrip) offers various advantages, namely the characteristics of a nonplanar waveguide can be obtained from SIW structures such as low insertion loss, low radiation loss, small EM interference, and low-cost fabrication.

The thin dielectric substrate on SIW does not allow transverse magnetic (TM) mode to resonate. Therefore, in SIW only the transverse electric (TE) mode can transmit effectively [10], [11]. In Figure 3 there are several important parameters to form the via wall. To find the diameter of the via, the distance between the via series, and the distance between the rows, following equation is used [12].

$$
\begin{gathered}
d<\frac{\lambda g}{5} \\
p \leq 2 d \\
a=\omega-\frac{d^{2}}{0.95 \times p}
\end{gathered}
$$

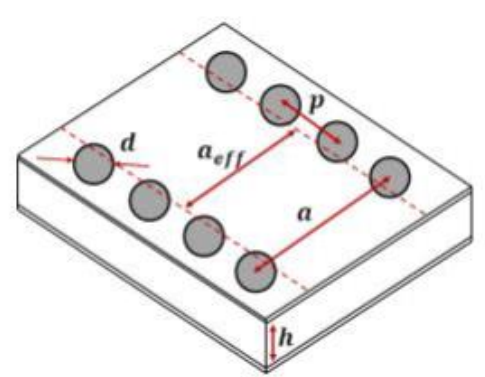

Figure 3. Via Structure on Substrate Integrated Waveguide [13]. 


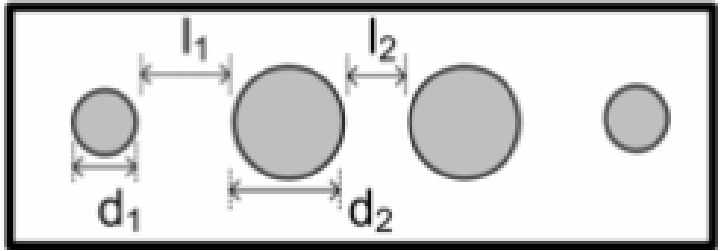

Figure 4. Structure of the Via Filter [14]

SIW filter can be designed using additional set of vias that is placed between the via walls. Figure 4 shows the parameters of the diameter and distance between the vias. To find these parameters, the following equation is used:

$$
\begin{gathered}
\omega=\frac{\omega_{2}-\omega_{1}}{\omega_{0}} \\
\omega \lambda=\frac{\lambda G}{\lambda_{0}} \omega
\end{gathered}
$$

after that, substitute the values in equations (4) and (5) as the parameters in the Chebyshev frequency response, in equations (6) and (7) [14].

$$
\begin{aligned}
& \frac{K_{01}}{Z_{0}}=\frac{K_{34}}{Z_{0}}=\sqrt{\frac{\pi}{2} \times \frac{\omega \lambda}{g_{0} g_{1} \omega_{1}}} \\
& \frac{K_{12}}{Z_{0}}=\frac{K_{23}}{Z_{0}}=\frac{\pi \omega \lambda}{2 \omega_{1}} \times \frac{1}{\sqrt{g_{1} g_{2}}}
\end{aligned}
$$

Then substitute equations (6) and (7) into equation (8). This equation calculates the final impedance for each stage in equations (6) and (7) [14].

$$
\frac{X_{j, j}}{Z_{0}}=\frac{K_{j, j+1} / Z_{0}}{1-\left(K_{j, j+1} / Z_{0}\right)^{2}}
$$

The dimensions of the via filter can be determined using the following equation [14]:

$$
\begin{gathered}
\theta_{j}=\pi-\frac{1}{2}\left(\tan ^{-1}\left(\frac{2 \times X_{j-1, j}}{Z_{0}}\right)+\tan ^{-1}\left(\frac{2 \times X_{j, j+1}}{Z_{0}}\right)\right. \\
l 1=l 3=\frac{\theta_{1} \times \lambda_{g}}{2 \pi}, l 2=\frac{\theta_{2} \times \lambda_{g}}{2 \pi}
\end{gathered}
$$

To match the impedance between the feed and the SIW components, a tapper is introduced to connect these two. The dimensions of the tapper can be determined using equations (13) and (14) [13].

$$
f c_{T E 10_{\text {siw }}}=\frac{c}{2 \sqrt{\varepsilon \Gamma}}\left(a-1.08 \frac{d^{2}}{p}+0.1 \frac{d^{2}}{p}\right)^{-1}
$$

$$
\begin{gathered}
f c_{T E 20_{\text {siw }}}=\frac{c}{\sqrt{\varepsilon \Gamma}}\left(a-\frac{d^{2}}{1.1 p}+0.1 \frac{d^{2}}{6.6 p^{2}}\right)^{-1} \\
l f 2=\frac{2 c}{3\left(1.25 \times f c_{T E 10_{\text {siw }}}+0.95 \times f c_{T E 20_{\text {siw }}}\right) \sqrt{\varepsilon \Gamma e}} \\
w f 2=\frac{c}{3\left(1.25 \times f c_{T E 10_{\text {siw }}}+0.95 \times f c_{T E 20_{\text {siw }}}\right) \sqrt{\varepsilon \Gamma e}}
\end{gathered}
$$

Before determining the dimensions of the filter, the first thing to consider is the order of the filter to be used. Based on the specifications, the most suitable frequency response is Chebyshev, with a ripple of $0.1 \mathrm{~dB}$. To determine the filter order (n), following equations are used:

$$
\begin{gathered}
F W B=\frac{\omega_{2}-\omega_{1}}{\omega_{0}} \\
\Omega_{s}=\frac{2}{F W B}\left(\frac{\omega_{2}-\omega_{1}}{\omega_{0}}\right) \\
n \geq \frac{\cosh ^{-1} \sqrt{\frac{10^{0.1 \times L A S}-1}{10^{0.1 \times L A R}-1}}}{\left.\cosh ^{-1} \Omega_{s}\right)}
\end{gathered}
$$

The next step is to calculate the diameter and distance between the via walls, then determine the diameter and distance between the filter vias. After that, the ratio between the length and width of the tapper is calculated. Finally, a 3-pole Chebyshev SIW filter based on the equation is shown in Figure 5 and the detailed parameter values are shown in Table 1.

The simulation results of the filter performance at the center frequency of $24 \mathrm{GHz}$ show the insertion loss of $4.0437 \mathrm{~dB}$, return loss $-4.0820 \mathrm{~dB}$, VSWR of 4.337 , and bandwidth of $256 \mathrm{MHz}$. These results did not meet the initial specifications. Therefore, an optimization step is carried out. Optimization by adding vias was carried out to obtain nearly ideal $S_{11} \& S_{22}$ parameters. Vias were added to guide the incoming waves from the feeder and tapper through the area with the via filter, and thus minimize the unwanted scattered waves.

In addition, vias located at the very end of both sides of the filter close to the tapper and feeder, are shifted by $0.8 \mathrm{~mm}$ to adjust the shape of the feeder and tapper. The purpose is to guide the incoming waves directly. The optimized design results are shown in Figure 6 and the dimensional changes are shown in Table 3.

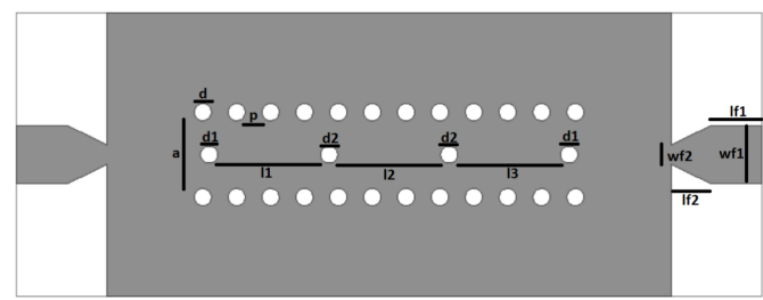

Figure 5. Filter Design. 
TABLE 1. DIMENSIONS OF THE FILTER

\begin{tabular}{|c|c|l|}
\hline No. & Parameter & \multicolumn{1}{|c|}{ Value (mm) } \\
\hline 1 & $\mathrm{~d}$ & 0.6 \\
\hline 2 & $\mathrm{p}$ & 1.2 \\
\hline 3 & $\mathrm{a}$ & 3.0014 \\
\hline 4 & $\mathrm{~d} 1$ & 0.6 \\
\hline 5 & $\mathrm{~d} 2$ & 0.6 \\
\hline 6 & $11 \& 13$ & 3.6449 \\
\hline 7 & 12 & 3.65 \\
\hline 8 & lf1 & 1.824930 \\
\hline 9 & wf1 & 2.043870 \\
\hline 10 & lf2 & 0.688445232 \\
\hline 11 & wf2 & 0.688445232 \\
\hline
\end{tabular}

Figure 7 depicts the result of optimization where the $\mathrm{S}_{21}$ parameter or insertion loss value has a slight change but still meets the requirement value. At the $23.5 \mathrm{GHz}$ frequency, which previously $-0.7120 \mathrm{~dB}$, the insertion loss decreases to $-1.1086 \mathrm{~dB}$, at the $24.5 \mathrm{GHz}$ frequency, which previously $-1.2473 \mathrm{~dB}$, the $\mathrm{S}_{21}$ decreases to $1.2689 \mathrm{~dB}$, while at the middle frequency which previously received $\mathrm{S}_{21}$ of $-0.9124 \mathrm{~dB}$, is now changes to $-0.6695 \mathrm{~dB}$. The lower stopband area was previously at $23.38 \mathrm{GHz}$, and after the optimization it has shifted slightly to $23.382 \mathrm{GHz}$. Meanwhile, the upper stopband, which was previously at $24.6320 \mathrm{GHz}$, has shifted to $24.6180 \mathrm{GHz}$. Moreover, the $\mathrm{S}_{11}$ or the return loss value has significantly changed but still meets the specification value and the resulting graphical shape is close to the ideal shape.

At the $23.5 \mathrm{GHz}$ frequency, the $S_{11}$ changes from 16.9193 to $-10.0260 \mathrm{~dB}$, at $24.5 \mathrm{GHz}$ frequency, the $\mathrm{S}_{11}$ changes from $-16.2063 \mathrm{~dB}$ to $-19.7888 \mathrm{~dB}$ while at the middle frequency, the $S_{11}$ changes from $-12.7049 \mathrm{~dB}$ to $36.9344 \mathrm{~dB}$. In case of the stopband, the lower stopband is shifted from $23.424 \mathrm{GHz}$ frequency to a frequency of $23.4690 \mathrm{GHz}$. Meanwhile, the upper stopband, which was previously at $24.6350 \mathrm{GHz}$, has shifted to 24.5990 $\mathrm{GHz}$.

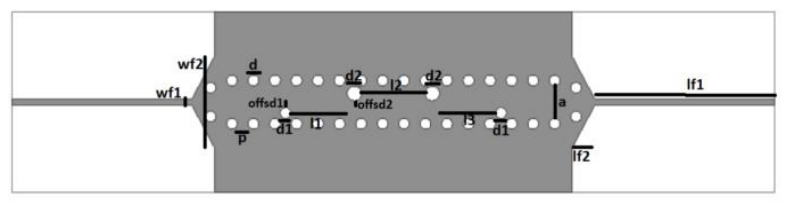

Figure 6. Optimization Result of the Filter Design.

TABLE 2. OPTIMIZATION PARAMETER

\begin{tabular}{|c|c|l|}
\hline No. & Parameter & \multicolumn{1}{c|}{ Value (mm) } \\
\hline 1 & $\mathrm{~d}$ & 0.6 \\
\hline 2 & $\mathrm{p}$ & 1.2 \\
\hline 3 & $\mathrm{a}$ & 2.4 \\
\hline 4 & $\mathrm{~d} 1$ & 0.6 \\
\hline 5 & $\mathrm{~d} 2$ & 0.8 \\
\hline 6 & $11 \& 13$ & 3.9473021532016 \\
\hline 7 & 12 & 3.5378823279004 \\
\hline 8 & lf1 & 10.039874138999 \\
\hline 9 & wf1 & 0.37783444116295 \\
\hline 10 & lf2 & 1.2341273596467 \\
\hline 11 & wf2 & 5 \\
\hline 12 & offsd1 & 0.48 \\
\hline 13 & offsd2 & 0.6 \\
\hline
\end{tabular}

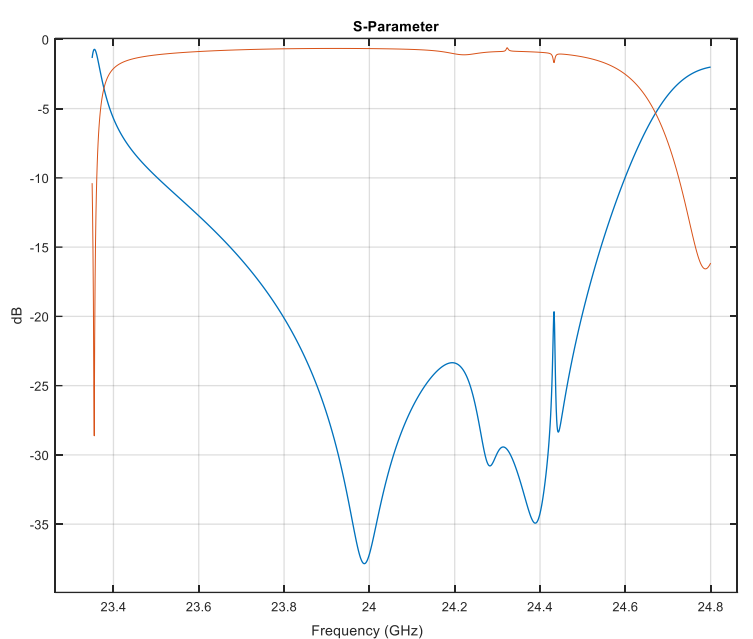

Figure 7. S-Parameter results.

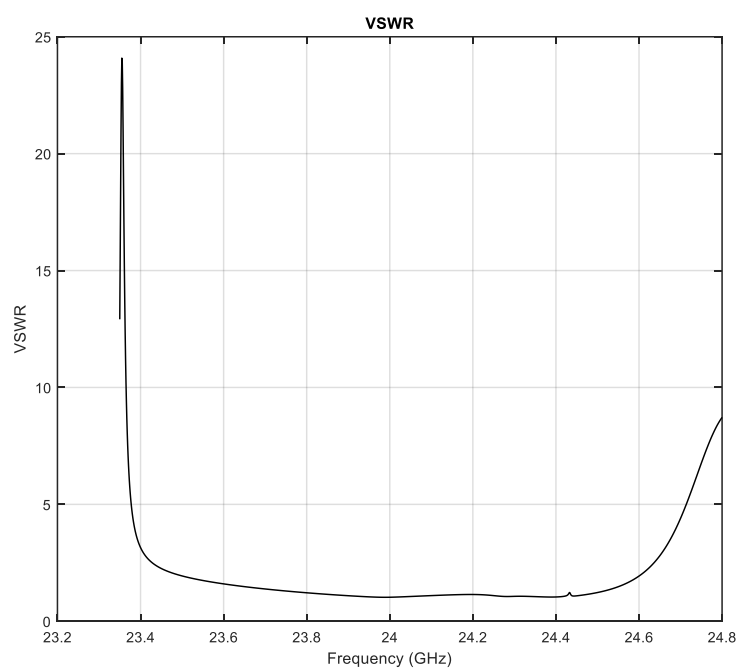

Figure 8. VSWR Result.

Figure 8 shows the VSWR value. There is a slight change but still meets the specification value. The VSWR at $23.5 \mathrm{GHz}$ frequency was previously 1.3319 , now is 1.9209 , at the $24.5 \mathrm{GHz}$ frequency, of the VSWR was previously 1.3602 , now is 1.2283 , while the VSWR at the middle frequency changes from 1.6028 to 1.0308 . The lower stopband area, which was previously at 23.4190 $\mathrm{GHz}$, has shifted to $23.4870 \mathrm{GHz}$. Meanwhile, the upper stopband, which was previously at $24.64 \mathrm{GHz}$, has shifted to $24.6060 \mathrm{GHz}$.

\section{FABRICATION, MEASUREMENT, AND DISCUSSION}

\section{A. Fabrication}

The proposed SIW filter is fabricated on RO4003C substrate with $0.813 \mathrm{~mm}$ thickness, as shown in Figure 9. The fabricated bandpass filter is measured using a microwave analyzer measuring instrument N9918A which has a measurement frequency range from $30 \mathrm{KHz}$ to $26.5 \mathrm{GHz}$. The measurement is carried out to find out the technical data from the proposed filter design, namely insertion loss, return loss, and VSWR. The measurement results data then will be compared with the design specification data. 


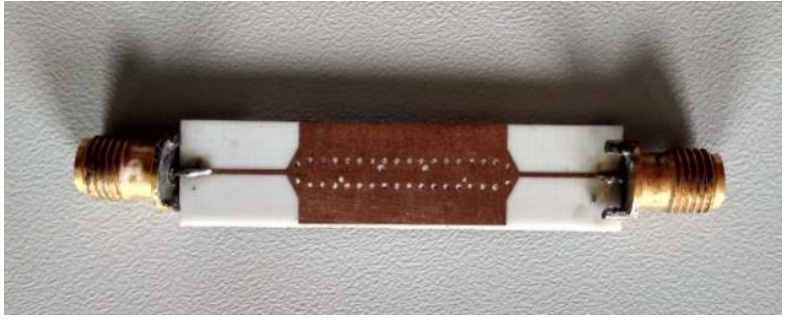

(a)

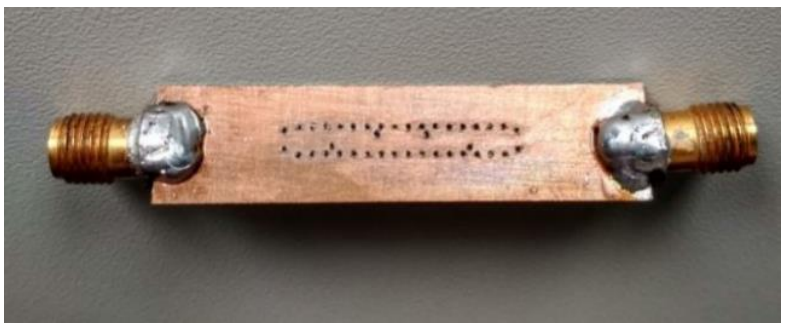

(b)

Figure 9. Fabricated Filter (a) Top View (b) Bottom View.

\section{B. Measurement}

Before starting a measurement, a calibration is carried out using a calibrator shown in Figure 10. In this step, it is found that there is a loss of $-0.8109 \mathrm{~dB}$ that will affect the measurement results. This is marked with a red box in Figure 10.

\section{Results and Discussion}

Figure 11 shows the measurement results of the $S_{21}$ or insertion loss parameter. Although there is a loss of $0.8109 \mathrm{~dB}$ from the measurement system, the device's performances still meet the pre-determined specification at 23.5 to $24.5 \mathrm{GHz}$. Considering the system loss, the $\mathrm{S}_{21}$ at $23.5 \mathrm{GHz}$ frequency is $-3.338 \mathrm{~dB}$ and at $24.5 \mathrm{GHz}$ is $4.814 \mathrm{~dB}$, while at $24 \mathrm{GHz}$ is $-4.316 \mathrm{~dB}$. It is seen in the graph, there is a change in the measured bandwidth.

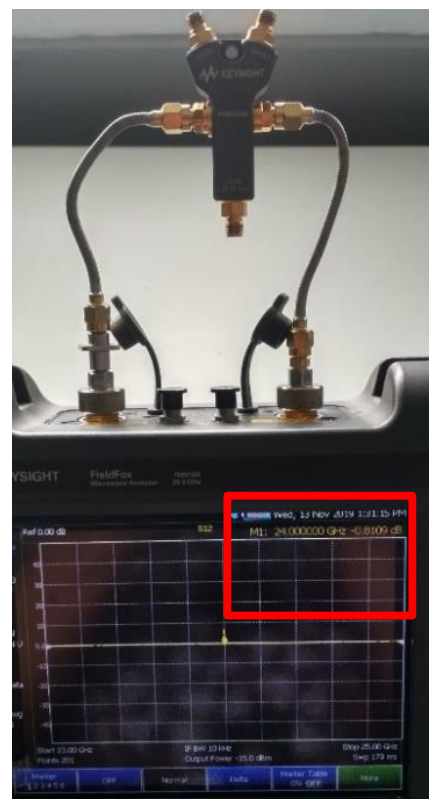

Figure 10. Measurement Calibration.

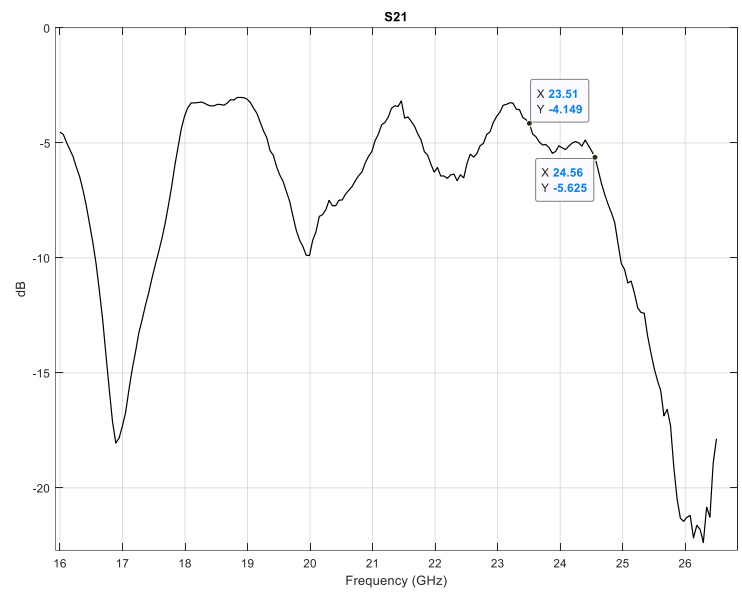

Figure 11. $\mathrm{S}_{21}$ Measurement Result.

Figure 12 shows the measurement results of the $S_{11}$ parameter or return loss. In the frequency range of 23.5 to $24.5 \mathrm{GHz}$, the value obtained still meets the specification target when the result has been reduced by the loss of $-0.8109 \mathrm{~dB}$ which was known from the previous calibration.

If the system loss is taken into account, the value of $\mathrm{S}_{11}$ at the $23.5 \mathrm{GHz}$ frequency is $-10.139 \mathrm{~dB}$, at $24.5 \mathrm{GHz}$ is $-10.969 \mathrm{~dB}$ while at the $24 \mathrm{GHz}$ frequency is -8.136 $\mathrm{dB}$. Similar to the previous $\mathrm{S}_{21}$ measurement, there is a shift in the $S_{11}$ of the bandpass section and it appears that the bandwidth is decreasing compared to the simulation.

Figure 13 shows a graph of VSWR measurement. The measured VSWR are 1.833 at $23.5 \mathrm{GHz}, 1.649$ at $24.5 \mathrm{GHz}$, and 2.067 at $24 \mathrm{GHz}$. Based on the overall measurement, all of the results at the frequency range of 23.5 to $24.5 \mathrm{GHz}$ still meet the requirements that are specified earlier. It is noted, however, that the measurement results are far from ideal. The measured operation frequency is slightly shifted and the bandwidth is reduced compared to the simulation results.

Based on the filter performance, although the insertion loss, return loss, and VSWR parameters still meet the initial specifications, there is a significant difference of the measured bandwidth parameter compared to the simulation. The summary of the performance results is shown in Table 3 .

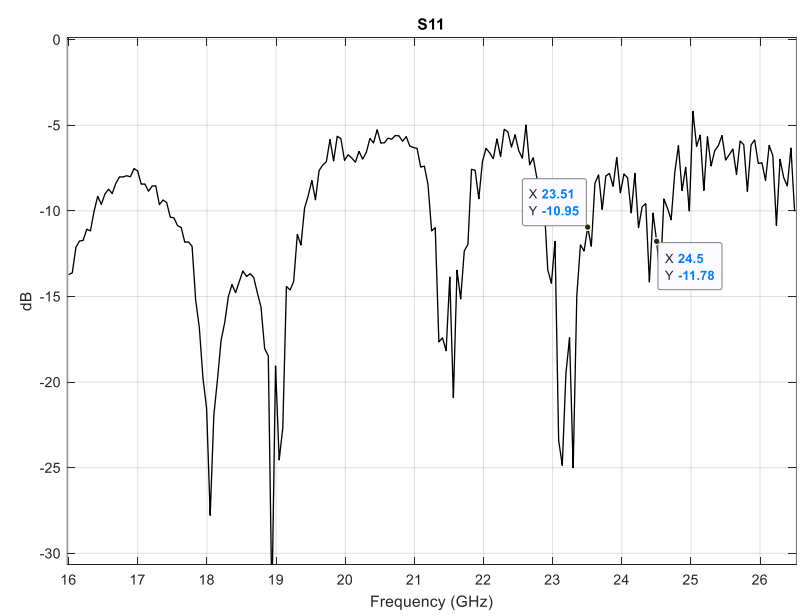

Figure 12. $\mathrm{S}_{11}$ Measurement Result. 


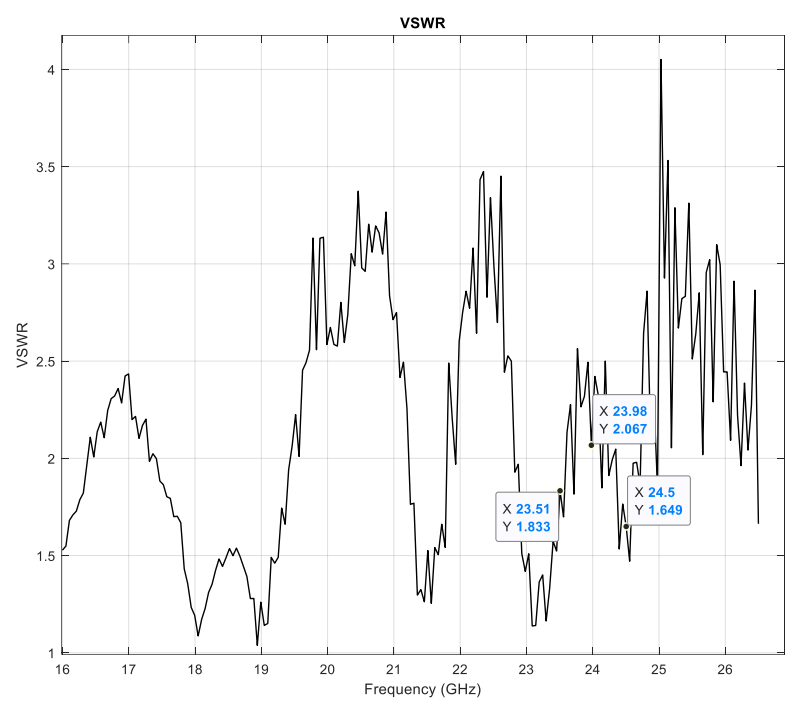

Figure 13. VSWR Measurement Result.

TABle 3. Summary of PERformanCE RESUlt

\begin{tabular}{|l|c|c|c|}
\hline \multicolumn{1}{|c|}{ Parameter } & Target & Simulation & Measurement \\
\hline VSWR & $\leq 2$ & 1.0308 & 2.067 \\
\hline Insertion Loss & $\geq-3 \mathrm{~dB}$ & $-0.6695 \mathrm{~dB}$ & $-4.316 \mathrm{~dB}$ \\
\hline Return Loss & $\leq-10 \mathrm{~dB}$ & $-36.9344 \mathrm{~dB}$ & $-8.136 \mathrm{~dB}$ \\
\hline Bandwidth & $1 \mathrm{GHz}$ & $1.236 \mathrm{GHz}$ & $580 \mathrm{MHz}$ \\
\hline
\end{tabular}

The bandwidth discrepancy that occur during the measurement can be ascertained due to the fabrication factors. Based on the formula used when performing calculations, the diameter of the via filter and the distance between the via filters have an influence on the generated bandwidth. In addition, the dimensions of the tapper also have a significant effect on the bandwidth and the value of other parameters, because this section is an adjustment between the feeder and the components of SIW.

Furthermore, the imperfect drilling process on the substrate in the SIW method also contributes to the result discrepancies. If the drilling process is done manually, there will be a possibility of size or placing inaccuracy that may affect the measured device's performances. In other words, a high precision fabrication is needed in the prototyping of the bandpass filter using the SIW method. In addition, fabrication losses may arise due to poor soldering of the connectors that can increase the attenuation of the filter.

\section{CONCLUSION}

We have designed and realized a bandpass filter using a substrate integrated waveguide structure. The design of the bandpass filter has a good agreement with the specification of short-range radar applications with a working frequency of $24 \mathrm{GHz}$. The realization of the bandpass filter gives good performances in terms of insertion loss, return loss and VSWR. Nevertheless, the bandwidth is reduced by about $50 \%$ compared with the simulation bandwidth. It is caused by the fabrication process such as hole drilling that requires precision. Furthermore, the change of the tapper dimension during the fabrication also influence the bandwidth.

\section{ACKNOWLEDGMENT}

Thanks to Pamungkas Daud, Deni Permana Kurniadi, Dadin Mahmudin from Research Center for Electronics and Telecommunication, LIPI for their valuable support during the design and measurement of this research activity. The authors also would like thank Dr. Yusuf Nur Wijayanto for his guidance and constructive suggestions during the research and paper writing activity.

\section{REFERENCES}

[1] M. I. Skolnik, Radar Handbook, 2nd ed., MacGraw-Hill, 1990.

[2] A. Caliskan, Y. E. Yamac, H. Uysal, A. S. Turk, A. Kizilay and M. Orhan, "24 GHz short range radar system measurements for synthetic aperture radar imaging," in Proc. Microwaves, Radar and Remote Sensing Symposium (MRRS), Kiev, 2017.

[3] Y. Ju, Y. Jin and J. Lee, "Design and implementation of a $24 \mathrm{GHz}$ FMCW radar system for automotive applications," in 2014 International Radar Conference, Lille, 2014.

[4] A. Rhbanou, M. Sabbane and S. Bri, "Design of K-Band Substrate Integrated Waveguide Band-Pass Filter with High Rejection," Journal of Microwaves, Optoelectronics and Electromagnetic Applications, vol. 14, no. 2, pp. 155 169, 2015.

[5] B. Rahali and M. Feham, "Design of K-band substrate integrated waveguide coupler, circulator and power divider," International Journal of Information and Electronics Engineering, vol. 4, no. 1, pp. 47-53, 2014.

[6] H. Serliningtyas, O. D. Winarko, Muhyin, A. A. Lestari and F. Y. Zulkifli, "Substrate Integrated Waveguide (SIW) Filter," in Seminar on Microwave and Antenna Propagation, Jakarta, 2014.

[7] A. Saputra, N. Ismail and A. Munir, "Perancangan Antena Mikrostrip Berbasis Substrate Integrated Waveguide (SIW) untuk Aplikasi WLAN," in Seminar on Microwave and Antenna Propagation, Jakarta, 2018.

[8] F. Grine, T. Djerafi, M. T. Benhabiles, K. Wu and M. L. Riabi, "High-Q Substrate Integrated Waveguide Resonator Filter With Dielectric Loading," IEEE Access, vol. 5, pp. 12526-12532, 2017.

[9] L. Ye, Y. Chen, K. D. Xu, W. Li, Q. H. Liu and Y. Zhang, "Substrate Integrated Plasmonic Waveguide for Microwave Bandpass Filter Applications," IEEE Access, vol. 7, pp. 75957-75964, 2019.

[10] N. D. Bismoko, "Perancangan Bandpass Filter Berbasis Substrate Integrated Waveguide (Siw) Dengan Metode Defected Ground Structure (Dgs) Untuk Aplikasi Ground Penetrating Radar (GPR) - Ultra Wideband (UWB)," Institut Teknologi Sepuluh Nopember, Surabaya, 2016.

[11] W. Waskito, "Perancangan dan analisis kinerja band pass filter berbasis substrate integrated waveguide untuk aplikasi ground penetrating radar ultra wideband pada frekuensi 2-2.5GHz," Institut Teknologi Sepuluh Nopember, Surabaya, 2016.

[12] A. O. Nwajana, A. Dainkeh and K. S. K. Yeo, "Substrate Integrated Waveguide (SIW) Bandpass Filter with Novel Microstrip-CPW-SIW Input Coupling," Journal of Microwaves, Optoelectronics and Electromagnetic Applications, vol. 16, no. 2, pp. 393-402, 2017.

[13] R. C. Caleffo, "New design procedure to determine the taper transition for impedance matching between microstrip line and SIW component," Journal of Microwaves, Optoelectronics and Electromagnetic Applications, vol. 15, no. 3, pp. 247-260, 2016.

[14] W.-G. Yeo, T.-Y. Seo, J. W. Lee and C. S. Cho, "H-plane sectoral filtering horn antenna in PCB substrates using via 
fences at millimetre-wave," in 2007 European Microwave Conference, Munich, 2007. 